\title{
Analysis of Three-Dimensional Pile Groups
}

M.T. Liang

Department of Harbor and River Engineering National Taiwan Ocean University Keelung 20224, Taiwan, Republic of China

Y. Liu

Department of Harbor and River Engineering National Taiwan Ocean University Keelung 20224, Taiwan, Republic of China

Follow this and additional works at: https://jmstt.ntou.edu.tw/journal

Part of the Civil and Environmental Engineering Commons

\section{Recommended Citation}

Liang, M.T. and Liu, Y. (1994) "Analysis of Three-Dimensional Pile Groups," Journal of Marine Science and Technology. Vol. 2: Iss. 1, Article 6.

DOI: $10.51400 / 2709-6998.2487$

Available at: https://jmstt.ntou.edu.tw/journal/vol2/iss1/6

This Research Article is brought to you for free and open access by Journal of Marine Science and Technology. It has been accepted for inclusion in Journal of Marine Science and Technology by an authorized editor of Journal of Marine Science and Technology. 


\title{
ANALYSIS OF THREE-DIMENSIONAL PILE GROUPS
}

\author{
M.T. Liang and Y. Liu \\ Department of Harbor and River Engineering \\ National Taiwan Ocean University \\ Keelung 20224, Taiwan, Republic of China
}

Key words: analysis, interaction, pile, reaction, stiffness.

\section{SUMMARY}

A numerical technique is presented in the analysis for loading behavior of general three-dimensional pile groups. The striking characteristics of the pile-group model may include raked pile, different pile sizes, non-uniform pile sections, soil inhomogeneit y, soil nonlinearity, and pile-soil-pile interaction. Atypical six-pile group is analyzed and the results are compared with that obtained by four other computer programs that are based on different approaches. The computed solutions are shown to have reasonally good agreement with the measured values.

\section{INTRODUCTION}

There are many numerical methods which are now available for the analysis of reactions of pile groups. For instance, Banerjee and Davies [1] developed a PGROUP program by using a boundary element method. This program is a nonlinear method of analysis in which volume cells were introduced in to the soil domain to handle soil yielding. Poulos [2] wrote a DEFPIG program using a simplified boundary element method for the single pile analysis and calculation in which the interaction factors for two equally loaded identical piles are considered. Soil nonlinearity is equivalent to limiting the stresses at the pile-soil interaction, whereas soil inhomogeneity is approached with an averaging procedure using the point-load solutions of Mindlin [3]. Randolf [4] assumed that soil behavior is linear elastic. The PIGLET program developed by Randolf is based on analytical solutions that are either derivatived theoretically or fitted to finite element results to give the response of single pile. Pile-soil-pile interaction is based on interaction factors determined from expressions fitted to the results of finite element analysis. Chow [5] directly considered pile-soil-pile interaction effects utilizing Mindlin's solution [3] for the analysis of the general three-dimensional pile group model.

This paper describes a method of analysis that combines the striking features in the general three-dimensional pile group model of Reese, et al [6] and O,Neill, et al [7]. The numerical process for three-dimensional pile-group analysis is useful for vertical pile groups subjected to axial and lateral loads. The accuracy of this suggested method is evaluated by comparing the approach with some computer proprams available for pile-group analysis for the performance of a typical battered pile group.

\section{ANALYTICAL METHOD}

Typical limitations in most methods for analyzing three - dimensional , batter - pile foundations are: (1) The structural pile cap is completely rigid, and (2) Axial, lateral, and total reactions to load are obtained by the principle of superposition. Fig. 1 shows a hypothetical structure supported by batter pile.

The superstructure is called the" general structure Cartesian coordinate system " $(\mathrm{X}, \mathrm{Y}, \mathrm{Z})$ with external load acting on the superstructure at the origin of that coordinate system. The coordinate of a particular pilehead (or pile-structure joint) are $\left(\mathrm{X}_{\mathrm{i}}, \mathrm{Y}_{\mathrm{i}}, \mathrm{Z}_{\mathrm{i}}\right)$. Each pile is further called a" local structure coordinate system" $\left(X_{i},{ }^{\prime}, Y_{i}^{\prime}, Z_{i}{ }^{\prime}\right)$. The orientation of each pile with reference to the local structure coordinate system is given by the direction angles $\xi, \lambda$ and $\omega$. An additional coordinate system, designated the "pile coordinate system "( $(\mathrm{u}, \mathrm{v}, \mathrm{w})$ is established as shown in Fig. 2. In the orthogonal system the $u$-axis is coincident with the longitudinal axis of the pile and is positive downward, while the w-axis is 


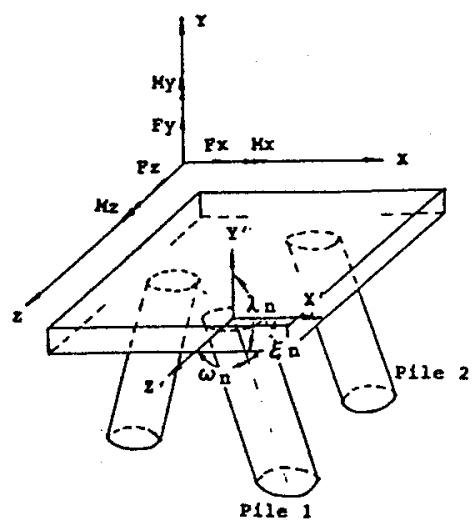

Fig. 1. Ahypothetical structure supported by batter pile.

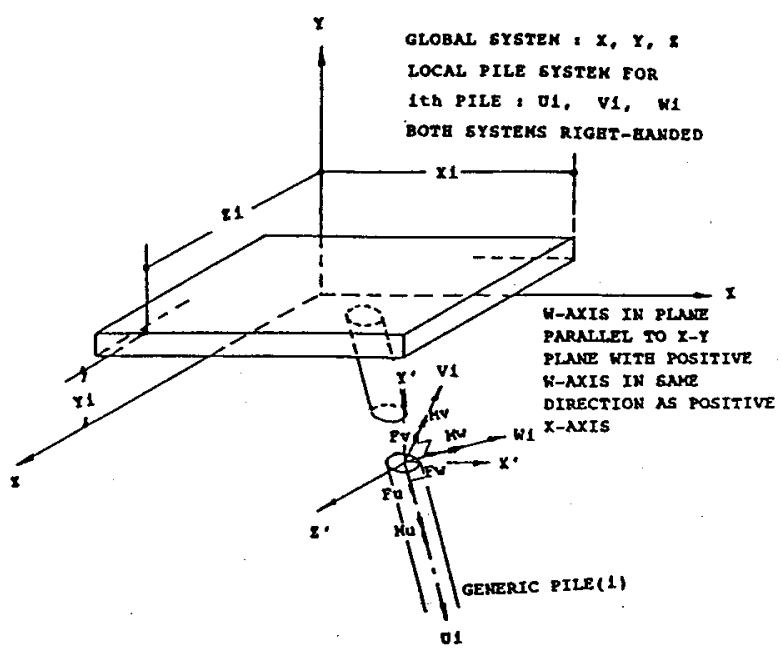

Fig. 2. Golbal and local cartesian coordinate system.

fixed in the $X_{i}^{\prime}-Y_{i}^{\prime}$ plane and the $v$-axis is pointed away from the reader.

Let $\mathrm{Ui}=$ reaction transformation matrix for pile $i$ then the reaction forces and moments $\{\mathrm{Fu}, \mathrm{Fv}, \mathrm{Fw}, \mathrm{Mu}, \mathrm{Mv}$, $\mathrm{Mw}\}_{\mathrm{i}}$ in the $\mathrm{u}, \mathrm{v}$ and $\mathrm{w}$ direction at joint $\mathrm{i}$ are first transformed into a vector $\{\mathrm{Fx}, \mathrm{Fy}, \mathrm{Fz}, \mathrm{Mx}, \mathrm{My}, \mathrm{Mz}\}_{(\mathrm{i})}$ with reference to the general structure coordinate system by the following matrix relationship (see Reese et al [6])

$$
U_{i} F_{i}=F_{(i)}
$$

At present, it is hoped that a transformation be developed from the structure movement vector $\{\Delta \mathrm{X}, \Delta \mathrm{Y}, \Delta \mathrm{Z}$, $\alpha \mathrm{X}, \alpha \mathrm{Y}, \alpha \mathrm{z}\}$ to the joint movement vector $\{\delta \mathrm{U}, \delta \mathrm{V}, \delta \mathrm{W}$, $\alpha \mathrm{U}, \alpha \mathrm{V}, \alpha \mathrm{W})_{\mathrm{i}}$. The notation $\Delta$ and $\delta$ indicate translations in the subscripted direction, while $\alpha$ indicates rotation about the subscripted axis. This transformation can be represented as

$$
T_{i} A=\delta_{i}
$$

where $\mathbf{T} \mathbf{i}=$ deformation transformation matrix for pile i, $A=$ structure movement vector, and $\delta \boldsymbol{\delta}=\varphi \operatorname{siv} \tau$ move-ment vector at pile $i$. By the relationship in geometry, one may obtain the following equation

$$
T_{i}=U_{i}^{T}
$$

Eq. (3) is valid for small displacement. Fig. 3 shows four modes of pile-head movement for establishing a stiffness relationship between reaction and movement of a single pile head. This relation can be expressed in matrix for as

$$
\left(\begin{array}{cccccc}
c_{5} & 0 & 0 & 0 & 0 & 0 \\
0 & c_{1} & 0 & 0 & 0 & c_{2} \\
0 & 0 & c_{1} & 0 & -c_{2} & 0 \\
0 & 0 & 0 & c_{6} & 0 & 0 \\
0 & 0 & -c_{2} & 0 & c_{4} & 0 \\
0 & c_{3} & 0 & 0 & 0 & c_{4}
\end{array}\right)_{i}\left(\begin{array}{c}
\delta u \\
\delta v \\
\delta w \\
\alpha u \\
\alpha v \\
\alpha w
\end{array}\right)_{i}=\left(\begin{array}{c}
F u \\
F v \\
F w \\
M u \\
M v \\
M w
\end{array}\right)_{i}
$$
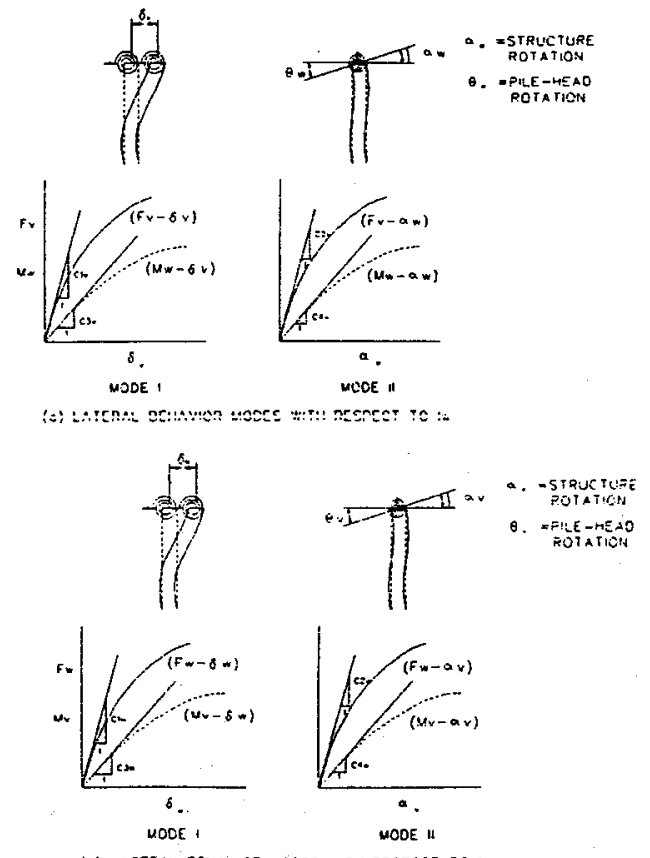

(b) Lateral gemaviof moOES WITH RESPECT 10 iv
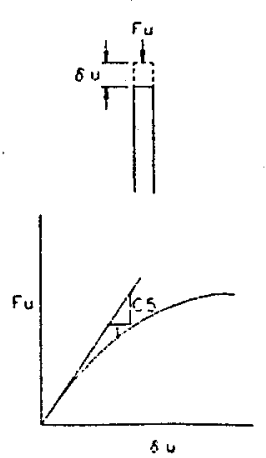

(c) MODE III (ARIA:
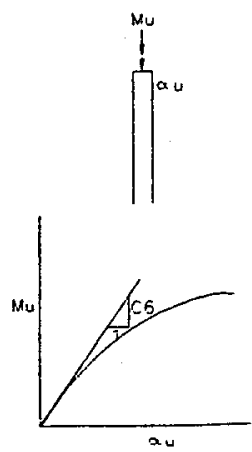

(d) MODE IV (TOFFSIOHAL
Fig. 3 Response foundation for pile-head (ater O'Neill et al (1997)). 
Eq. (4) is stated more concisely as

$$
S_{i} \delta_{\mathrm{i}}=F_{i}
$$

where $\mathrm{Si}=$ pile-head stiffness matrix. The structure stiffness matrix can be obtained from Eqs. (2), (3) and (5) as

$$
F_{(i)}=U_{i} S_{i} T_{i} A
$$

For equilibrium of the superstructure

$$
\sum_{i=1}^{N} F_{(i)}=F
$$

where $\mathrm{N}=$ pile number and $\mathrm{F}=$ vector of applied forces and moments.

Let

$$
R_{i}=U_{i} S_{i} U_{i}^{T}
$$

and define the structure stiffness matrix

$$
R=\sum_{i=1}^{N} R_{(i)}
$$

then the force-deformation relationship of the entire system can be written as

$$
F=R A
$$

The problem of three - dimensional grouped piles thus reduces to solve Eq. (10) for A. The F-vector is known, and $R$, a $6 \times 6$ matrix, can easily be calculated by taking the algebraic sum of the Ri matrices.

\section{COMPUTATIONAL PROCEDURE}

The numerical procedure of Reese, et al [612] was improved by O'Neill, et al [7] through the incorporation of pile-soil-pile interaction effects utilizing Mindlin's solutions [3]. The computational procedure is illustrated in Fig. 4. In order completel y to compute the additional displacement, the original noninteractive unit soil reaction relationships should be modified as shown in Fig. 5. Let $d_{u f i}$ is the total additional displacement of the soil around the $\mathrm{I}_{\mathrm{th}}$ node parallel to the axis, and $\delta_{\mathrm{uri}}$ be the axial displacement of the pile at the same point obtained from the noninteractive analysis, then a factor $Z_{\mathrm{Ii}}$ is computed for each end node on the $I_{t h}$ pile and is written as

$$
Z_{I i}=\frac{d_{u I i}+\delta_{u l i}}{\delta_{u l i}}
$$

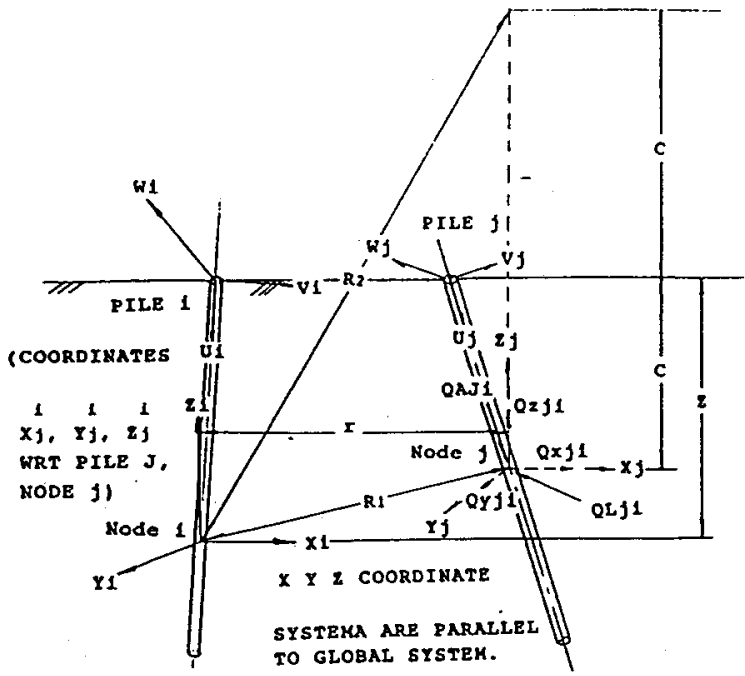

Fig. 4. Coordinate system for computing added displacement at pile I, node $\mathrm{i}$.

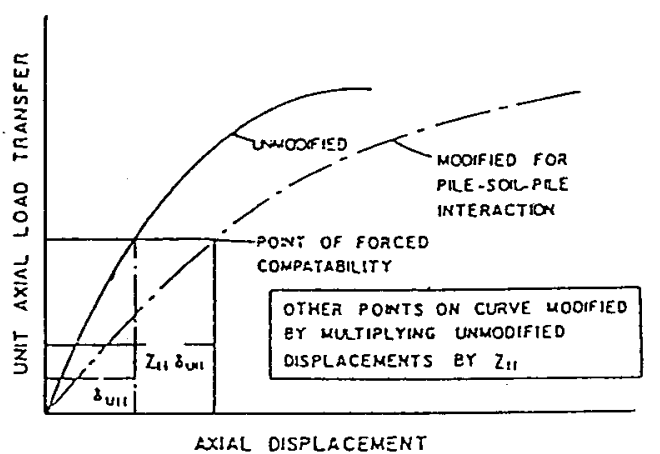

Fig. 5. Modification of unit axial soil resistane relationship for group effects at pile $I$, node $i$.

eq.(11) was built assuming $d_{u I i}$ and $\delta_{u \mathrm{ui}}$ being in the same direction. However, if the two displacements are in opposite directions and the absolute value of $\mathrm{d}_{\mathrm{Ii}}$ equals or exceeds that of $\delta_{\mathrm{Ii}}$, then the modifier becomes

$$
Z_{I i}=\frac{\left|\delta_{u l i}\right|}{\left|\delta_{u I i}\right|+\left|d_{u i i}\right|}
$$

\section{EXAMPLE PROBLEM}

Fig.6 illustrates the pile-group configuration which indicates a model test on a battered pile group subjected to a combined vertical load of $222 \mathrm{~N}$ and a horizontal load of $138 \mathrm{~N}$ in fine, fairly uniform sand (see Davisson and Sally [14] and Chow [5]). The aluminum pipe pile has an outer diameter of $12.7 \mathrm{~mm}$ with $0.8 \mathrm{~m}$ wall thickness, and an embedded length of $533 \mathrm{~mm}$.

In order simply to analyze, the pile cap is assumed 

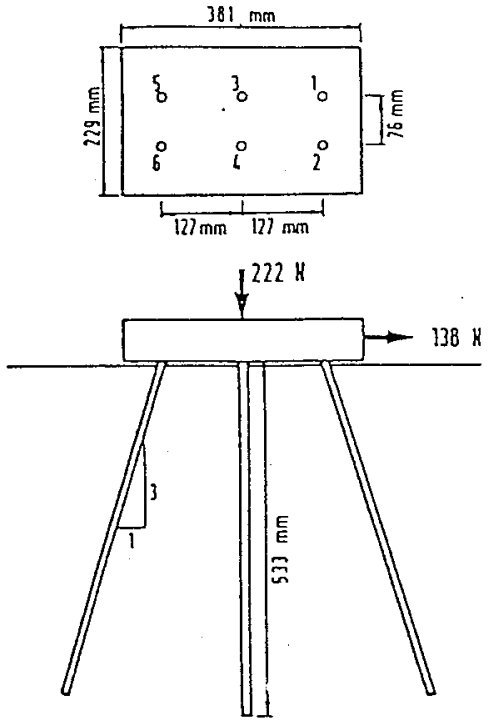

Fig. 6. Details of pile group model.

to be rigid and is permitted rotation. The soil Young's modulus is assumed to vary linearly with depth, and is taken to be $19,000 \mathrm{kpa} / \mathrm{m}$. The Poisson's ratio of the soil is assumed to be 0.3 .

The analytical procedure has been programmed by the digital computer. Its utility and the significance of three-dimensional geometry and pile-soil-pile interaction are demonstrated in a practical example mentioned earlier. Given parameters: (1) external forces are listed in Table.1 and Fig. 6. (2) The response module of piles (Assume that all the pile have the same values.) are shown in Table. 2. (3) The coordinates and orientations of piles are presented in Table. 3. The units of position are meter. The results of numerical calculation for this example are shown in Table. 4, 5 and 6. To illustrate in more detail, the results (Fig. 7-12) presented by three-dimensional coordinates are expressed that the grouped pile the variation of displacement and rotation in $\mathrm{X}, \mathrm{Y}$ and $\mathrm{Z}$ direction.

The computed horizontal deflection of $0.24 \mathrm{~mm}$ is in good agreement with the measured value of $0.23 \mathrm{~mm}$. Table.7 summarizes the measured and computed moments, shear, and axial loads at the pile heads, as well as solutions from Chow [5], PGROUP (Banerjee and Davies [1]) and PIGLET (Randolph [4]). There is a general agreement among the four theoretical approaches and the measured results in terme of relative magnitudes of the moments and loads, but the trends of the moment/load distributions differ somewhat.

\section{DISCUSSION}

The computational results in this study reveal several important facts which are shown as follows.

1. Compared with external force induced moment,
Table 1. applied loads

\begin{tabular}{|lrl|}
\hline Fx & 0 & N \\
Fy & -222 & N \\
Fz & 138 & N \\
Mx & 0 & NM \\
My & 0 & NM \\
Mz & 0 & NM \\
\hline
\end{tabular}

Table 2. The response modulus of piles

\begin{tabular}{|c|cccccc|}
\hline PILE NO & $\begin{array}{c}\mathrm{c}_{1} \\
\mathrm{kN} / \mathrm{M}\end{array}$ & $\begin{array}{c}\mathrm{c}_{2} \\
\mathrm{kN} / \mathrm{M}\end{array}$ & $\begin{array}{c}\mathrm{c}_{3} \\
\mathrm{kN} / \mathrm{M}\end{array}$ & $\begin{array}{c}\mathrm{c}_{4} \\
\mathrm{kN} / \mathrm{M}\end{array}$ & $\begin{array}{c}\mathrm{c}_{5} \\
\mathrm{kN} / \mathrm{M}\end{array}$ & $\begin{array}{c}\mathrm{c}_{6} \\
\mathrm{kN} / \mathrm{M}\end{array}$ \\
\hline 1 & 35.0 & 1750.0 & 1750.0 & 3500.0 & 87.5 & 5250.0 \\
2 & 35.0 & 1750.0 & 1750.0 & 3500.0 & 87.5 & 5250.0 \\
3 & 35.0 & 1750.0 & 1750.0 & 3500.0 & 87.5 & 5250.0 \\
4 & 35.0 & 1750.0 & 1750.0 & 3500.0 & 87.5 & 5250.0 \\
5 & 35.0 & 1750.0 & 1750.0 & 3500.0 & 87.5 & 5250.0 \\
6 & 35.0 & 1750.0 & 1750.0 & 3500.0 & 87.5 & 5250.0 \\
\hline
\end{tabular}

Table 3. The coordinates (unit:M) and orientation of eachpile

\begin{tabular}{|c|ccccr|}
\hline Pile No & $\mathrm{X}$ & $\mathrm{Y}$ & $\mathrm{Z}$ & alpha & batter \\
\hline 1 & .038 & .0 & .127 & .0 & 3.0 \\
2 & -.038 & .0 & .127 & .0 & 3.0 \\
3 & .038 & .0 & .0 & .0 & 100.0 \\
4 & -.038 & .0 & .0 & .0 & 100.0 \\
5 & .038 & .0 & -.127 & .0 & 3.0 \\
6 & -.038 & .0 & -.127 & .0 & 3.0 \\
\hline
\end{tabular}

Table 4. The foundation displacements and rotation in $X, Y$, $\mathbf{Z}$ direction

\begin{tabular}{|l|l|l|l|}
\hline $\mathrm{x}=$ & .017882 & alpha $\mathrm{x}=$ & -.002718 \\
$\mathrm{y}=$ & -.071116 & alpha $\mathrm{y}=$ & -.000387 \\
$\mathrm{z}=$ & -.020350 & alpha $\mathrm{z}=$ & -.000849 \\
\hline
\end{tabular}

Table 5. The foundation displacement, rotation, force, and moment in $\mathrm{u}, \mathrm{v}, \mathrm{w}$ direction

\begin{tabular}{|l|cccccc|}
\hline pile & $\Delta \mathrm{u}$ & $\Delta \mathrm{v}$ & $\Delta \mathrm{w}$ & $\alpha \mathrm{u}$ & $\alpha \mathrm{v}$ & $\alpha \mathrm{w}$ \\
\hline 1 & .4159 & .0283 & -.0349 & -.0014734 & .0047793 & -.0137912 \\
2 & .4156 & .0285 & -.0348 & -.0014734 & .0047793 & -.0137912 \\
3 & .4073 & .0283 & .0988 & .0029633 & .0047793 & -.0135949 \\
4 & .4070 & .0285 & .0988 & .0029633 & .0047793 & -.0135949 \\
5 & .4194 & .0283 & -.0353 & -.0014737 & .0047793 & -.0137972 \\
6 & .4191 & .0285 & -.0325 & -.0014734 & .0047793 & -.0137912 \\
\hline pile & $\mathrm{Fu}$ & $\mathrm{Fv}$ & $\mathrm{Fw}$ & $\mathrm{Mu}$ & $\mathrm{Mv}$ & $\mathrm{Mw}$ \\
\hline 1 & 36.39 & -23.14 & -9.59 & -7.743 & 77.83 & 1.21 \\
2 & 36.36 & -23.14 & -9.58 & -7.743 & 77.63 & 1.61 \\
3 & 35.64 & -22.72 & -4.91 & 15.563 & -156.12 & 2.06 \\
4 & 35.61 & -22.71 & -4.91 & 15.563 & -156.12 & 2.45 \\
5 & 36.70 & -23.14 & -9.60 & -7.743 & 78.49 & 2.21 \\
6 & 36.67 & -23.14 & -9.59 & -7.743 & 78.29 & 1.61 \\
\hline
\end{tabular}


Table 6. Individual pile force components and checking sum of forces along

\begin{tabular}{|c|rrrrrr|}
\hline pile no & \multicolumn{1}{|l}{ Fx } & \multicolumn{1}{c}{ Fy } & \multicolumn{1}{c}{ Fz } & Mx & \multicolumn{1}{c|}{ My } & \multicolumn{1}{c|}{ Mz } \\
\hline 1 & 2.414 & -37.555 & 23.145 & 3.473 & 7.149 & -79.260 \\
2 & 2.408 & -37.525 & 23.137 & 3.844 & 9.032 & -76.206 \\
3 & -4.907 & -35.641 & 22.722 & 2.059 & -16.421 & 154.766 \\
4 & -4.907 & -35.609 & 22.714 & 2.453 & -14.694 & 157.474 \\
5 & 2.499 & -37.850 & 23.145 & -6.103 & 6.525 & -79.926 \\
6 & 1.493 & -37.820 & 23.137 & -5.725 & 8.409 & -76.849 \\
& .000 & -222.00 & 138.00 & -.000 & .000 & .000 \\
& $(.000)$ & $(-222.00)(138.00)$ & $(.000)$ & $(.000)$ & $(.000)$ \\
\hline
\end{tabular}

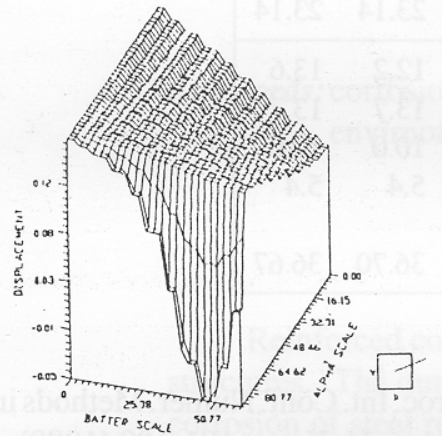

Fig. 7. The foundation displacement in X-direction.

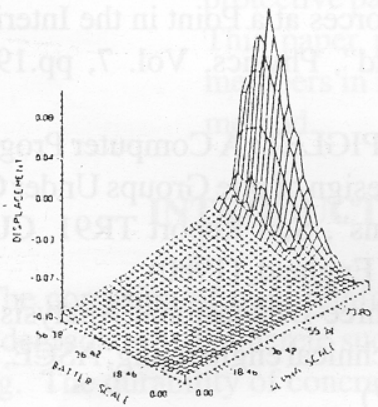

Fig. 8. The foundation displacement in Y-direction.

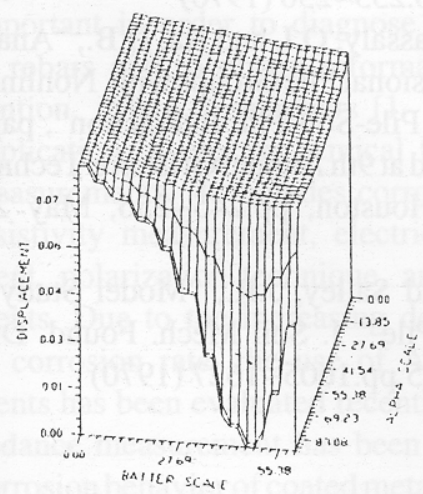

Fig. 9. The foundation displacement in Z-direction.

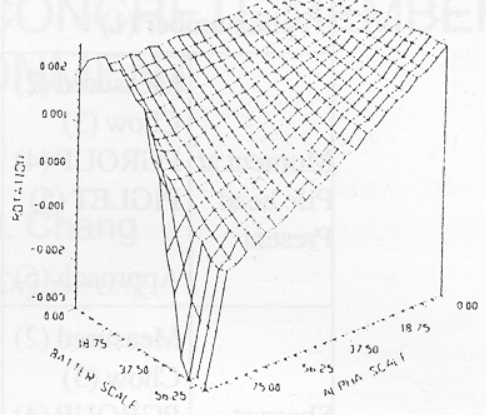

Fig. 10. The fonudation rotation in X-direction.

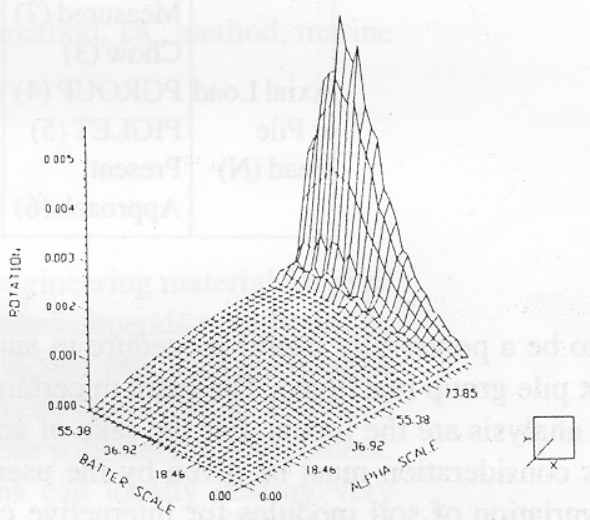

Fig. 11. The foundation rotation in Y-direction.

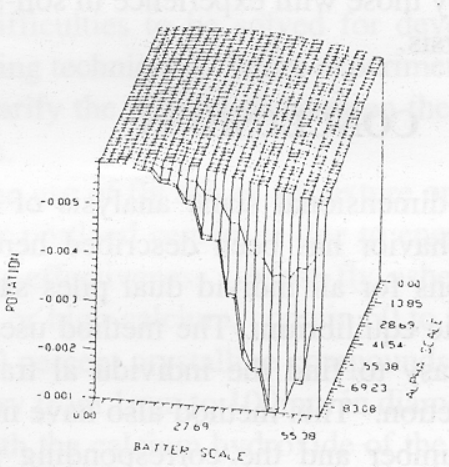

Fig. 12. The foundation rotation in Z-direction.

there are $5 \times 10^{-6} \%$ and $1 \times 10^{-6} \%$ errors for computational moment in $\mathrm{X}$ - and $\mathrm{Y}$ - direction, respectively, due to computer selection and justification. However, these errors are allowable.

2. In practice, the pile cap is flexible rather than rigid. It needs further studying to consider the effect of pile- cap flexibility.

3. The method developed in this paper has been 
Table 7. Comparison with Model Test Results

\begin{tabular}{|c|c|c|c|c|c|c|c|}
\hline \multicolumn{2}{|c|}{ pile number (1) } & 1 & 2 & 3 & 4 & 5 & 6 \\
\hline \multirow{5}{*}{$\begin{array}{l}\text { Moment at } \\
\text { Pile head } \\
\text { Present }\end{array}$} & ed (2) & 1.30 & 1.27 & 1.20 & 1.18 & 1.49 & 1.22 \\
\hline & & 1.55 & 1.55 & 1.36 & 1.36 & .53 & 1.53 \\
\hline & PGRC & 1.06 & 1.26 & 1.13 & 13 & 23 & 1.23 \\
\hline & PIGLET (5) & 1.18 & 1.17 & 1.17 & 1.17 & 1.55 & 1.55 \\
\hline & Approac & 1.21 & 1.61 & 2.06 & 2.45 & 1.21 & 1.61 \\
\hline \multirow{5}{*}{$\begin{array}{l}\text { Shear at } \\
\text { Pile Head } \\
\text { Present }\end{array}$} & & 22.2 & 23.1 & 169 & 6 & 5 & 16.9 \\
\hline & & 20.0 & 20.0 & 16.1 & & & 9.0 \\
\hline & & 16.5 & 16.5 & & 1 & 3.7 & 18.7 \\
\hline & PIGLET (5) & 14.4 & 14.4 & 14.1 & 14.1 & 19.6 & 19.6 \\
\hline & Approach (6) & 23.14 & 23.14 & 22.72 & 22.71 & 23.14 & 23.14 \\
\hline \multirow{6}{*}{$\begin{array}{l}\text { Axial Load } \\
\text { at Pile } \\
\text { Head (N) }\end{array}$} & & & & & & & \\
\hline & Cho & 63.5 & 63.5 & 38.2 & 38.2 & 13.7 & 13.7 \\
\hline & PGROUP (4) & 68.1 & 68.1 & 36.5 & 36. & 10.0 & 10.0 \\
\hline & PIGLET (5) & 73.8 & 73.8 & 34.6 & 34.6 & 5.4 & 5.4 \\
\hline & Preser & & & & & & \\
\hline & & & 30.30 & 30.0 & 35.01 & 30.10 & \\
\hline
\end{tabular}

shown to be a powerfully useful procedure in analyzing complex pile group reactions. The main uncertainties in such an analysis are the inputs. For the sake of accuracy rigorous consideration must be given by the user to set up the variation of soil modules for interactive calculations and until soil resistance curves that are representative of the site and loading conditions the calculation should never be stopped. Straight choice of these inputs is not always straight forward; hence, the method should be used solely by those with experience in soil-structure interaction analysis.

\section{CONCLUSIONS}

The three-dimensional static analysis of offshore grouped-pile behavior has been described herein. The resultant reactions for all individ dual piles satisfy the equation of static equilibrium. The method used in this paper is very easy to find the individu al translation, rotation and reaction. This method also have no limitation for pile number and the corresponding position. Hence this procedure is a very useful engineering tool and a crucial valuable instrument for analysis of groupedpile (include latter) foundation design.

\section{REFERENCES}

1. Banerjee, P.K., and Davies, T.G., "Analysis of Some Reported Case Histories of Laterally Loaded Pile
Groups", Proc. Int. Conf. Numer. Methods in Offshore Piling, London, U. K., pp.101-108 (1980)

2. Poulos, H.G.. "An Approach for the Analysis of Offshore Pile Groups". Proc. Int. Conf. Numer. Methods. In Offshore Piling, London, U.K. pp.119 126 (1980)

3. Mindlin, R.D., "Forces at a Point in the Interion of a Semi-Infinite Soild", Physics, Vol. 7, pp.195 202, May, (1936)

4. Randolph, M.F.," PIGLET: A Computer Program for the Analysis and design of pile Groups Under General Loading Conditions", Soil Report TR91, CUED/D. Cambridge Univ., England, (1980)

5. Chow, Y. K., " Three-Dimensional Analysis of Pile Groups", J. Geotechnical engineering, ASCE, 113(6), pp.637 651 (1987)

6. Reese, L.C., O'Neill, M.W. and Smith, R.E., "Generalized Analysis of Pile Foundations", Journal of the soil Mechanics and Foundations Division, ASCE, Vol.96, No.SMI, pp.235 250 (1970)

7. O'Neill, M.W., Ghassaly, O.I. and Ha, H.B., "Analysis of Three-Dimensional Pile Groups with Nonlinear Soil Response and Pile-Soil-Pile Interaction", paper OTC 2838 presented at 9th Annual Offshore Technology Conference, Houston, pp.245 256, May 2-5, (1997)

8. Davisson, M.T. and Salley, J.R., "Model Study of Laterally Loaded Pile", J. Soil Mech. Found. Div., ASCE, Vol.96, No.5,pp.1605 1627 (1970) 